\title{
TEACHING PROFESSIONAL DEVELOPMENT AT UNIVERSITY: A PERSPECTIVE FROM LEADERSHIP
}

\author{
Vicente Carrasco Embuena \\ María José Hernández Amorós \\ University of Alicante
}

\begin{abstract}
:
This paper shows the results from a study on a teaching professional development project which has involved many teachers at the University of Alicante (Spain). The project main objective is to promote a change in the teaching professional culture. The findings indicate that it has been widely disseminated within the University and has succeeded in transforming the teachers' attitudes. The results allow to describe the characteristic features of the kind of leadership in the project and to know the perception that team coordinators have about the achievements made, especially its contribution to a professional improvement for teachers.
\end{abstract}

Keywords: Higher Education; academic leadership; teaching professional development.

Corresponding author: Vicente Carrasco Embuena

E-mail: vicente.carrasco@ua.es

Submitted for publication 06/09/2012

Accepted for publication 16/10/2012

Educational Research eJournal ISSN 2254-0385

(C) Faculty of Education. University of Alicante

DOI: 10.5838/erej.2013.21.04 


\section{Introduction}

The University of Alicante (Spain) decided to implement a teaching professional development project during the 2001/02 academic year, Networks for Research on University Teaching Project (NRUTP). It was an innovative proposal which represented an alternative to the traditional teacher training models based on learning teaching skills. That project suggested the constitution of knowledge and practice communities with the aim of designing and developing true learning processes (Wenger, 1998, 2000; Pisano \& Verganti, 2008; Thomas \& Brown, 2008; Gallagher, Griffin, Ciuffetelli-Parker, Kitchen \& Figg, 2011). It started from the conviction that the teachers' professional development must be based on their creativity and their capacity for innovation. It consequently avoided the conception of training understood as a transmission of universal formulas and, instead, encouraged participants to get involved in processes which had to be developed in flexible, bureaucracy-free environments, with a proclivity for boosting innovation. The NRUTP was structured in networks formed by teachers who associated themselves by affinity in groups created to address and investigate the problems and needs arising in their teaching practice (Hanna, 1998; CochranSmith \& Lytle, 1999; Burnaford et al., 2001; Cochran-Smith \& Zeichner, 2005; Brockbank \& McGill, 2007). During the subsequent academic years, the NRUTP has experienced a significant growth, both in the number of participants and in the quality of their research works (Details can be found at the institutional website:http://www.ua.es/en/ice/redes/ind ex.html)

In 2006, the NRUTP was already consolidated and its promoters decided to research into its development in order to improve it and make everybody aware of all the new possibilities it opened. The attention was focused on three aspects: participation, leadership and advice. This paper deals with the second of these three aspects, that is, the leadership emerging from the NRUTP. The goal is to identify the academic profiles of those who have been its main driving forces and to provide their vision about the effectiveness of the research carried out by the researchers' networks they coordinate, regarding objective attainment. Burns stated nearly forty years ago that "leadership is one of the most observed and least understood phenomena" (1978, p. 2). This opinion is still relatively valid in the context of Higher Education today, as it continues to be a dynamic, complex and multidimensional phenomenon (Filan \& Seagren, 2003; Scott, 2010) that researchers have analysed and interpreted from different perspectives (Koen \& Bitzer, 2010), identifying it as a specific, observable fact, although there is still no clear consensus when it comes to identify the characteristics of leaders (Buller, 2006, p. 159). The university's organisational complexity, together with its multiple objectives and its traditional values, make the nature of leadership at Higher Education ambiguous and controversial (Petrov, 2006). Therefore, a lot of research still needs to be done in this area, our modest aim in this paper being to make a contribution to that effort.

The constant adjustments suffered by Higher Education in recent years have turned it into an area of incessant farreaching turbulence (Hanna, 2003; Chetty \& Lubben, 2010). Aware of that complexity, researchers such as Lees (2006, p. 333) have even wondered how sane and rational individuals could possibly aspire to become academic leaders. At present, leadership has a complex meaning which is shaped in relation to the needs, aspirations and expectations both of the leaders themselves and of those who decide to work side by side with them (Keith \& 
Levin, 2002). In fact, it is interpreted as an "effort of collaboration between the group members" (Morrill, 2007, p. 19; Astin \& Astin, 2000, p. 9) because the role and functions of academic leadership include motivating and directing efforts to ensure transformation from collaboration. That is probably why it is one of the main strengths which allow universities to cope with the competitive environment where they live (Ramsden, 1998, p. 4). Some authors have actually described the current leaders as "the brokers of time and relationships" (Krahenbuhl, 2004, p. 48).

Transactional and transformational leadership paradigms have dominated academic research since 1960 (Van Zyl, 2008; Kezar et al., 2006, p. 108). The transformational leadership focused on the interactions between leaders and followers is an emergent idea within the university context (Kezar et al. 2006, p. $35)$. The key factor lies in its "potential to motivate the academic community to provide an effective response to changes", which is not only designed to satisfy and commit individuals but also to become a source of inspiration for staff members, administrators and students (Barling \& Turner, 2005, p. 1; Filan \& Seagren, 2003, p. 26; Kelly, 2003, p. 1; Astin \& Astin, 2000, pp. 8-9). This is the idea underlying the NRUTP, and the present paper is dedicated to its study.

The solutions imported from the private sector to Higher Education institutions are often based on principles and approaches derived from outdated ideas and management trends which have already been abandoned in the sector where they were originated (Birnbaum 2000a \& $2000 \mathrm{~b}$ ). Furthermore, universities have cultural features that make the adoption of those principles highly problematic. Several authors have highlighted this circumstance (Birnbaum, 1988; Bergquist, 1992) together with the need to realign the direction of leadership change within the university culture (Kezar \& Eckel,
2002; Lueddeke, 1999; Middlehurst, 1997). At the same time, the confrontation between management principles and leadership culture has been widely documented (Chandler et al., 2002), although it would be advisable to adapt that controversy to the Higher Education context.

The principles of distributed leadership offer many possibilities at any university. On the one hand, the notion of distributed leadership fits in well with those of collegiality and professional autonomy, which have been traditional characteristics of leadership at universities; and, on the other hand, it recognises the far-reaching needs for the institutional management of changes that present-day international contexts impose on Higher Education institutions.

A growing body of research has been dedicated to the study of scientific leadership as a shared or distributed phenomenon, questioning its traditional conception as an exclusively vertical process where an individual leader is the main source of influence. Alternatively, distributed leadership focuses on the mechanisms through which various individuals contribute to the leadership process, shaping the collective action that provides a complementary understanding of the subtleties offered by leadership for the real configuration of organisations.

Research on distributed leadership is still in its infancy; in fact, there is not even a single univocal concept of distributed leadership yet (Bennett et al., 2003; Day et al., 2004). Some authors use the term 'shared leadership' (Pearce, 2004; Pearce \& Sims, 2002), while others prefer to talk about 'distributed leadership' (Gronn, 2002). No conceptual differences exist between these two approaches and some authors actually use both expressions interchangeably (Day et al., 2004). Most of them agree on the two principles underpining the concept: on the one hand, it is a shared influence 
to which several people contribute; and, on the other hand, it emerges from the interactions between the different individuals, who form a group or network where expert quality is distributed among all of them (Feyerherm, 1994; Pearce, 2004; Ensley et al., 2006).

This research developed exactly at the moment when the NRUTP became fully consolidated within the university fabric and quite visible in its teaching culture. This was possible thanks to the work of leaders who were able to persuade their colleagues to join research teams, encouraging them to design and develop projects with the aim of improving their teaching, as well as the students'. Projects that have additionally contributed to forge their own identity and build up their professional development. We have looked into those projects trying to identify the aspects which shape the identity of those leaders and obtain evidence on how they perceive and value the work of the groups they coordinate. Therefore, this research has two objectives:

1.To identify the characteristic features of the teachers who head research projects on university teaching.

2.To know their perception about the degree of objective attainment in the NRUTP, especially in what regards its contribution to the professional improvement of teachers and its impact on the students' learning through seven indicators: innovation; effects on learning; impact of the teachers' professional improvement; viability; attention to individual differences; adaptation to the peculiarities of the different degrees; and prominence of participants.

The coordinators' opinions constitute a valuable source to evaluate the NRUTP by their strong commitment to it and, above all, by their thorough knowledge not only of the projects and the structures on which they are supported but also of the teachers who implement them.

\section{Methodology}

All the teachers who coordinated networks were asked to answer an anonymous survey with closed-ended questions available through the on-line form that had been previously inserted in the Instituto de Ciencias de la Educación [Education Sciences Institute] web page (Appendix I). The questionnaire was validated by taking into account the suggestions of two expert colleagues who were consulted and by administering it in advance to five randomly chosen leaders, whose answers led to the introduction of several modifications. It was filled in by 34 out of 59 coordinators who received it, which represents $57.6 \%$ of the NRUTP leaders.

The reason for the choice of a closed questionnaire was, in the first place, the fact that it complemented the semistructured interviews used in the other two NRUTP studies performed regarding participation and advice (two aspects which are not going to be addressed in this paper for space reasons) and, in the second place, the economy of time, the fact that it was easy to be answered and, especially, its suitability for the achievement of the sought objectives. The coordinators were asked to fill in the questionnaire as an important part of the NRUTP improvement process that had been undertaken from different perspectives.

We have selected the leaders' opinions by means of intentional sampling for two reasons: because it is one of the editions with the highest number of participants, so it represents the largest population that can be studied; and because, given the high 'loyalty' rates in the NRUTP, it includes many of the coordinators from previous editions and represents the 
universe of participating leaders. Although it is not a representative sample obtained through random sampling, the indiscriminate collection of questionnaires makes it comparable, as the study considers every completed form, which corresponds to more than $50 \%$ of the interviewed leaders.

\section{Results}

\subsection{Socio-demography of leadership in the NRUTP}

The participating leaders were asked to provide different socio-demographic data, which made it possible to define their characteristic features, especially:

\subsubsection{Coordinators' age}

Table 1 shows a vision of the leaders stratified by age ranges. Globally speaking, the distribution replicates the population formed by the whole University of Alicante (UA) teaching staff. These ranges have highly homogeneous values and present low dispersion among them (Cfr. Standard Deviation-SD- values).

\begin{tabular}{lccc}
\hline Age & $\begin{array}{c}\% \\
\text { Networks }\end{array}$ & \% UA & SD \\
\hline $31-35$ & 23.5 & 17.2 & 4.5 \\
$36-40$ & 20.6 & 24.5 & 2.8 \\
$41-45$ & 20.6 & 19.4 & 0.8 \\
$46-50$ & 17.6 & 16.2 & 1.1 \\
$51-55$ & 8.8 & 11.0 & 1.6 \\
55 or & 8.8 & 11.7 & 2.0 \\
more & & & \\
\hline
\end{tabular}

Table 1.Leaders' age

\subsubsection{Seniority as teachers}

Table 2 includes the teaching experience of the leaders. The sample offers a normal distribution with a predominance of ranges corresponding to central values (between 6 and 10 and between 11 and 15 years of experience as teachers). It is worth mentioning the heterogeneity in the values for those teachers with less than 5 years of seniority, which results from the influence exerted by Profesores Asociados [ASO, professionals who work as part-time lecturers with a contract that is renewed every year], whose number has been growing considerably since 2001 (when the University Act currently in force was enacted). It is a group with high rotation rates and their dedication to university is practically confined to teaching.

\begin{tabular}{lccc}
\hline $\begin{array}{l}\text { Years of } \\
\text { experience }\end{array}$ & $\%$ & $\begin{array}{r}\% \\
\text { UA }\end{array}$ & SD \\
\hline Less than 5 & 8.8 & 38.3 & 20.8 \\
$6-10$ & 41.2 & 30.3 & 7.7 \\
$11-15$ & 26.5 & 19.4 & 5.0 \\
$16-20$ & 14.7 & 10.1 & 3.3 \\
$21-25$ & 8.8 & 1.9 & 4.9 \\
\hline
\end{tabular}

Table 2. Seniority as teachers

\subsubsection{Centres to which leaders belong}

Table 3 offers an overview of the centres where the leaders develop their professional activity. Those who provide a higher number of coordinators are the Higher Polytechnic School (EPS, for its Spanish initials) and the Faculties of Science, Economics and Business, Education, and Letters; in other words, those with more weight at the UA. The contribution made by smaller centres such as the Higher Schools of Nursing, Labour Relations, and Optics and Optometry is also outstanding in relative terms. At the other end, the Law Faculty provides no leaders despite its relevance within the University as a whole (this faculty hosts $16 \%$ of the students enrolled at the UA).

\subsubsection{Coordinators' category}

professional

Table 4 shows the stratification of the coordinators by professional categories. Profesores Contratados Doctores [CD, Lecturers with a $\mathrm{PhD}$ working with a contract] and Profesores Titulares de Escuela Universitaria [TEU, Higher School or Technical College Full Lecturers, a post for which a $\mathrm{PhD}$ is not 
required] are the most numerous ones, followed in importance by Profesores Titulares de Universidad [TU, University or Faculty Senior Lecturers]. The other categories are represented too, namely: Catedráticos de Universidad [CU, University Professors] and Ayudantes Doctores $[\mathrm{AD}$, literally Assistant Doctors, i.e. Assistant Lecturers with a $\mathrm{PhD}$ ]. However, once again, Profesores Asociados [ASO, professionals who work as part-timer lecturers with a contract that is renewed every year] have no representation. None of the coordinators belongs to this group.

\begin{tabular}{lccc}
\hline Faculties & $\%$ & \% UA & SD \\
\hline Nursing & 8.8 & 5.5 & 2.4 \\
Optics and Optometry & 2.9 & 2.7 & 0.2 \\
Higher Polytechnic & 32.4 & 25.6 & 4.8 \\
Science & 29.4 & 17.5 & 8.4 \\
Economics and Business & 8.8 & 20.8 & 8.5 \\
Education & 8.8 & 6.8 & 1.4 \\
Letters & 5.9 & 17.5 & 8.2 \\
Labour Relations & 2.9 & 3.6 & 0.4 \\
\hline
\end{tabular}

Table 3. Faculties and centres

\subsubsection{Distribution by departments}

Table 5 permits to verify that the sample under study includes 18 out of the 53 departments existing at the University of Alicante. Thus, it comprises one third of its department structures belonging to the main centres, which in turn are the ones that provide the largest number of students and sustain its demographic structure.

\begin{tabular}{lccc}
\hline $\begin{array}{l}\text { Professional } \\
\text { Categories }\end{array}$ & $\%$ & $\%$ UA & SD \\
\hline CU & 8.8 & 17.6 & 6.2 \\
TU & 35.3 & 42.2 & 4.9 \\
TEU & 50.0 & 38.5 & 8.1 \\
AD & 5.9 & 1.7 & 3.0 \\
\hline
\end{tabular}

Table 4. Professional category

Likewise, 22 knowledge areas distributed across the different disciplines are represented as well. Therefore, the sample is also representative of the different University department areas regarding this variable.

The preceding data permit to be optimistic about the leaders' capacity to transform the teaching culture at university. It is well-known that institutions constantly change, although in most cases, those changes do not alter them to a significant extent, either because they only affect some isolated segments of the organisation or because the context does not respond to them. As suggested by Eckel, Hill \& Green (1998), the innovation that generates a real transformation must alter the corporate culture and affect assumptions, processes and products. It must be a deep and penetrating change, intentional and sustained over time, which impacts on the institution as a whole. The aforementioned dimensions of leadership addressed by the NRUTP and the performance of its leaders seem to fit in with a process of this kind.

\subsection{Leaders' perceptions about objective attainment}

The leaders were consulted on seven broad themes. Table 6 shows those focuses of interest along with their relative importance. The standard deviation (SD) corresponding to the values of each item is 7.5 and Pearson's variation coefficient $(\mathrm{Cv})$ is 0.29 . Both measures express a data homogeneity, what reflects the compactness of the leaders' answers, thus underlining their balance and soundness. 


\begin{tabular}{lc}
\hline Departments & $\%$ \\
\hline Nursing & 8.8 \\
Optics Interuniversity Institute & 2.9 \\
Computer Languages and Systems & 5.9 \\
Chemical Engineering & 5.9 \\
Sociology II, Psychology & 5.9 \\
Physics and Systems Engineering & 14.7 \\
Statistics and Operational Research & 2.9 \\
Analytical Chemistry & 11.8 \\
Ecology & 2.9 \\
Computing Science & 8.8 \\
Contemporary Humanities & 2.9 \\
General and Specific Didactics & 2.9 \\
Catalan Studies & 2.9 \\
Graphic Expression and Cartography & 5.9 \\
Community Nursing and Public Health & 2.9 \\
Innovation and Didactic Training & 2.9 \\
English Studies & 5.9 \\
Physiology and Genetics & 2.9 \\
\hline
\end{tabular}

Table 5. Distribution by departments

\begin{tabular}{lc}
\hline Themes & $\%$ \\
\hline $\begin{array}{l}\text { They raise new, original aspects related to teaching } \\
\text { research }\end{array}$ & 70.6 \\
$\begin{array}{l}\text { They have an effect on the students' learning } \\
\text { They play a relevant role in the teachers' professional }\end{array}$ & 94.1 \\
$\begin{array}{l}\text { improvement } \\
\text { There are real possibilities to implement them in practice }\end{array}$ & 79.4 \\
$\begin{array}{l}\text { They are sensitive and/or pay attention to the teachers' } \\
\text { characteristics }\end{array}$ & 47.1 \\
$\begin{array}{l}\text { They respond to the peculiarities of the different subjects } \\
\text { and/or degrees }\end{array}$ & 82.1 \\
$\begin{array}{l}\text { They give relevant prominence to the participants in the } \\
\text { research process }\end{array}$ & 47.1 \\
\hline
\end{tabular}

Table 6. Themes in the Cridu Questionnaire

\subsubsection{Participants' Prominence}

Table 6 makes clear that nearly half of the coordinators believe that the teachers involved in networks assume a very prominent role in the development of their research projects. This is consistent with a conception of teacher training which adopts as its starting point the recognition and acceptance of their vital experience, their academic training and their professional culture. Numerous authors (Stenhouse, 1980; Kennedy \& Kennedy, 1996; Cohen \& Hills, 2001; Kubitskey \& Fishman, 2006) have pointed out that one of the factors among those which have a special impact on education quality can be found in the innovation processes that involve the teaching staff in the production of curricular changes, demanding the use of alternative teaching materials and practices. This conception of educational innovation is an effective strategy for professional development because it makes teachers become protagonists, encouraging them to think and adopt decisions about their practice and about the innovation process itself, which 
acquire a true meaning for them. Participants experience -in the course of their own training- the teaching and learning processes as something valuable enough to be developed with their students. This permits to achieve a twofold purpose: familiarising teachers with their uses, advantages and difficulties; and inducing them to acquire new habits, skills and attitudes (Hanna, 2003).

\subsubsection{Response to the peculiarities of each subject and/or degree}

As it is collected in Table 6, more than $82 \%$ of the leaders consider that the research initiatives respond to the needs of subjects and/or degrees. One of the essential goals of the NRUTP has been to help teachers give a response to the new needs arising from the European convergence process, especially those related to the curricular design of subjects, disciplines and degrees. A wide range of actions (seminars, document distribution, preparation of computer applications, personalised advice, etc.) have been undertaken to that aim, seeking to advice research groups in terms of guiding criteria, which have always been offered as support elements and never as prescriptions. The variety of approaches that curricular planning can adopt has been harmonised with a certain degree of homogeneity so as to ensure syllabus transparency and facilitate the students' mobility. That is probably one of the reasons which explain the high degree of coincidence in the opinions of the network coordinators.

\subsubsection{Attention to the teachers' sensitivity and/or characteristics}

Almost half of the coordinators believe that the research work carried out by the teachers who participate in the networks is strongly linked to their characteristics. This result makes it clear that there are two distinct realities at the UA: that of teachers involved in the NRUTP, whose research initiatives are identified by their convictions, sensitivities and cultures; and that of a significant group of teachers who do not take part in those teaching innovation projects, either because they do not know about them or because they do not share their philosophy and adopt a reactive or indifferent position towards them.

\subsubsection{Possibilities to be implemented in practice}

$97 \%$ of the interviewed leaders think there are effective chances to implement the planned projects. They are aware of the fact that these projects have helped teachers distinguish the intuitive knowledge about teaching and learning from what is obtained from a professional perspective. This belief is based on the fact that they have checked the formative value:

-Of the study, analysis and reflection on the teaching practice

-Of shared analysis processes

-Of interdisciplinarity

-Of drawing up research reports which facilitate the public dissemination of results, sending them to the consideration of the academic community, who has welcomed them with great interest.

\subsubsection{Impact on the teachers' professional improvement}

As shown in Table 6, nearly $80 \%$ of the coordinators feel that the research projects have an effect on the professional improvement of those involved in them. Just like the participating teachers, they perceive that the processes of reflection, awareness, questioning and analysis focused on the teaching practice are elements which decisively help them shape their professional identity through shared learning experiences. They consider that the group's beliefs, thoughts and attitudes provide a wider and more enriching perspective than the individual 
view when it comes to find solutions to problems. Nevertheless, they do not forget the relevance that each teacher has as an individual, since they are aware of the fact that improvement processes need to be placed within their own personal and professional experiences (Wasser \& Bresler, 1996). On the other hand, they are conscious of the value reflexive dialogue has as a tool to solve organisational problems, in the sense described by many management researchers (Schon, 1983; Senge, 1990; Isaacs, 1999; Nehring, Laboy \& Catarius, 2010)

For coordinators, it is equally unquestionable that the teachers' participation in the NRUTP has allowed them:

-To adopt a new approach to the procedures and techniques used to estimate the time and effort students dedicate to achieve the learning objectives proposed to them.

-To ease a change in their attitudes towards teaching, focusing it on the students' work and not on their own teaching performance.

-To encourage the students' participation and autonomy, boosting their willingness to continue learning throughout their lives.

-To compare methodologies and contribute to create a teaching context which offers structural conditions for the methodological renewal to be successful.

-To acquire new professional competences (capacity to select and prepare disciplinebased contents, communication, didactic use of technology, introduction of new methodologies, design and implementation of alternative assessment modalities, etc.).

-To acquire skills in educational research which have allowed them to approach the teaching-learning process beyond didactic interaction, evaluating it and foreseeing its successive stages.

In short, the essential improvement the NRUTP has offered those involved in it has been to link their research processes with good teaching practices. The methodological change proposed entails the search for strategies and materials which effectively support and guide the students' work. Furthermore, it triggers the emergence among teachers of a collective awareness about the need to implement a curricular organisation that can prevent redundancies, loopholes and overlaps, besides guaranteeing a true sequencing of learning experiences.

\subsubsection{Influence on students' learning}

Over $94 \%$ of the leaders think that the research carried out by their teams has an impact on the students' learning. This means an almost unanimous support to the link between teaching innovation and learning improvement.

One of the deepest motivations for teachers in order to incorporate new methodologies into their practice lies in trying to improve their students' learning quality. Creating environments focused on it, reformulating assessment activities or stressing the acquisition of professional competences are proposals which do not fit in well with traditional methodologies and demand an additional effort on the teachers' part.

Participants in the NRUTP have performed educational tests with a view to improve the students' learning experiences and increase the academic success rates. They try to train students using proposals that force them to socialise, discuss what they have learnt, share ideas and meanings, check information, adopt decisions jointly, etc. That is why they have implemented methodological proposals which favour the cooperative search for meanings or the shared construction of knowledge and, at the same time, provide orientation for the development of competences, skills, attitudes and values.

These methodological suggestions have a strong impact on the students' motivation. We have checked how they feel highly 
encouraged when they assume the role of professionals who can find solutions to the problematic situations placed before them by teachers. It is also worth highlighting that these proposals permit to work with conceptual, procedural and attitudinal contents in parallel, thus facilitating the development of competences such as decision-making, empathy, dialogue or ethical understanding, which are not usually included in traditional syllabuses.

We have checked elsewhere in the study that many teachers perceived and ensured the link between their teaching research work and the improvement learning among their students, whereas others were more reluctant to accept that correlation. Coordinators have no doubts about this correlation though.

\subsubsection{Provision of new, original aspects related to teaching}

More than $70 \%$ of the leaders believe that the research developed within the NRUTP reveals new aspects associated with research on university teaching. It may seem a distorted perception if it is interpreted in the sense that they represent ex novo creations, but it must not be understood like this. The expression 'educational innovation' is difficult to conceptualise, although Nichols (1983) already defined it as the idea, object or practice perceived as new by an individual or individuals which tries to bring improvements regarding the sought objectives, which has a solid foundation, and which is planned and discussed.

Strictly speaking, the term 'new' means 'not invented', 'not known' or 'not done', that is, something generated or presented for the first time. Taking 'new' with this meaning may lead to a practical impossibility of undertaking any really innovative educational processes. Therefore, in the context of innovation, we regard as new all that refers to new ways of doing or using something, which can previously exist or even be known, although it is used for a different purpose, in different formats or with a different structure or organisation. In this sense Richland (cited by Morrish, 1976) conceives it when he states that it is the selection, organisation and creative utilisation of human and material resources, by means of new procedures, what permit to reach more valuable goals and objectives than those achieved in the past. In any case, true innovation is different from just 'cosmetic' changes in that it is long-lasting and linked to educational improvement.

It can consequently be stated that the definitions given by Richland \& Nichols are still valid. Innovation is essentially the effort made by someone to achieve a consistent, sound improvement in a given knowledge area. For that reason, it is a planned action implying a change which is not evolutionary or fortuitous, but intentionally sought, planned and developed. It has the aim to alter the existing reality through the modification of conceptions and attitudes, the alteration of methods and interventions, and the improvement or transformation depending on the case- of teaching and learning processes. It is consequently associated with change and has an (explicit or hidden) ideological, cognitive, ethical and emotional component.

Innovation is not undertaken from isolation or solitude, but from permanent exchange and cooperation. It is controversial as well as a source of permanent intellectual agitation. It is a process which requires a combination of events, individuals, situations and institutions interacting over a period of time to achieve a specific objective. We find ourselves before an essentially complex phenomenon which causes significant changes in educational systems and demands new relationships and behaviours between those who teach and those who learn. Therefore, it 
requires new values and demands renewed attitudes and practices. Within the university context, educational innovation is one of the axes contemplated in nearly all the strategic plans of Higher Education institutions.

The perspective adopted by the network coordinators when they state so categorically that teaching research offers new, original aspects related to teaching is based on the arguments exposed in the preceding paragraphs.

\section{Discussion and conclusions}

The analysis of the socio-demographic characteristics emerging from the data collected about the network coordinators permits to conclude that this leadership structure is highly distributed across the academic fabric, with great capacity to mobilise and influence colleagues so that they can identify and carry out shared intentions and goals (Leithwood, 2009, p. 20). Thus, they attest that:

a)Age is not an influential factor when it comes to assume leadership in research teams.

b)The centres providing a higher number of leaders are also those with more weight at the University, with the exception of the Law Faculty.

c)The predominant professional category among coordinators is that of Profesores Titulares de Universidad (TU, University or Faculty Senior Lecturers), on whom academic management basically relies.

d)Leaders belong to a wide range of departments as well as to a variety of knowledge areas, so replicating the socio-academic characteristics shown by the University of Alicante in both dimensions.

The leaders of the NRUTP consequently have features which include the conditions required to boost the two main functions of academic leadership: offering directions to its teams on common goals; and influencing its members so that they can work and do research on those goals.

In addition to that, their perception about the extent to which the objectives of the NRUTP have been fulfilled, and more precisely about the consolidation of collaborative work and the involvement of teachers, reinforces the conclusions drawn from the contributions made by the participating teachers. Leaders argue that these research initiatives have a pragmatic orientation, are linked to the teaching practice, and grant a very prominent role to teachers. All of this encourages them to assume a higher commitment level and increases the vitality of collaborative work.

Moreover, they think that research has an important and unquestionable impact on learning improvement and academic performance. Their opinion is conclusive: over $94 \%$ of the leaders are convinced of it. As it has been documented, the teaching task carried out by teachers is the most directly related factor to the students' learning results. However, that impact is moderated by other variables, such as the organisational environment and the action of leaders, which favour the creation of conditions and contexts where teachers can better develop their professional activity (Day et al., 2009; Seashore-Louis et al., 2010). The coordinators' perception about the research processes developed by the networks agrees with that of the teachers. They know how important these processes are for the teachers' professional development, since more than $70 \%$ of the coordinators consider that they offer new, original aspects associated both with approaches to teaching and with the research processes linked to it.

Finally, regarding the contribution this 
project made to the training of university teachers, nearly $80 \%$ of the leaders think that initiatives such as the Network for Research on University Teaching Project have a strong impact on the teachers' professional improvement. They underline two of its characteristics in particular: the attention paid to the peculiarities and needs of the teachers and the response to the particularities of the different subjects and degrees. These two proposals are supported by $66 \%$ and $82 \%$ of the leaders respectively. Therefore, in tune with Pont et al. (2008, p. 10), they decidedly align themselves with the so-called vision of leadership for learning, assuming that the main orientation for academic leadership lies on the students' learning improvement.

\section{References}

Astin, A. W. \& Astin, H.S. (2000). Leadership reconsidered: Engaging Higher Education in social change. Battle Cree, Michigan: WK Kellogg Foundation. [Full text] [Back to text]

Barling, J. \& Turner, N. (2005). Transformational leadership and moral reasoning: Social responsibility. Canadian Business, 78(12), 25-27. [Back to text]

Bennett, N., Harvey, J. A., Wise, C., \& Woods, P. A. (2003). Desk study review of distributed leadership. Nottingham: National College for School Leadership. [Full text] [Back to text]
Bergquist, W. H. (1992). The four cultures of the academy. San Francisco: Jossey-Bass Publishers. [Abstract] [Back to text]

Birnbaum, R. (1988). How colleges work: The cybernetics of academic organization and leadership. San Francisco: Jossey-Bass. [Abstract] [Back to text]

Birnbaum, R. (2000a). Management fads in Higher Education: Where they come from, what they do, why they fail. San Francisco: JosseyBass. [Abstract] [Back to text]

Birnbaum, R. (2000b). The life cycle of academic management fads. The Journal of Higher Education, 71, 1-16. [Abstract] [Back to text]

Brockbank, A., \& McGill, I. (2007). Facilitating reflective learning in Higher Education. Maidenhead, England: McGraw Hill/Society for Research into Higher Education and Open University Press. [Full text] [Back to text]

Buller, J. L. (2006). The essential department chair. A practical guide to college administration. Bolton: Anker. [Abstract] [Back to text]

Burnaford, G., Fischer, J. \& Hobson, D. (2001). Teachers Doing Research. The Power of Action through Inquiry. New Jersey: Lawrence Erlbaum Associates. [Full text] [Back to text]

Burns, J. (1978). Leadership. New York, NY: Harper \& Row. [Back to text]

Cochran-Smith, M. \& Lytle, S. L. (1999). Relationship of knowledge and practice: Teacher learning in the communities. Review of Research 
in Education, 24, 249-305. [Abstract] [Back to text]

Cochran-Smith, M. \& Zeichner, K. M. (2005). (Eds.). Studying teacher education: The report on the AREA Panel on research and teacher education. Mahwah, MJ: Lawrence Erlbaum. [Full text] [Back to text]

Cohen, D.K. \& Hills, H.C. (2001). Learning Policy: When State Education Reform Works. New Haven, CT: Yale University Press. [Full text] [Back to text]

Chandler, J., Barry, J., \& Clark, H. (2002). Stressing academe: The wear and tear of the new public management.Human

Relations, 55,1051-1069.[Full text] [Back to text]

Chetty, R. \& Lubben, F. (2010). The scholarship of research in teacher education in a Higher Education institution in transition: Issues of identity. Teaching and Teacher Education, 26, 813-820. [Full text] [Back to text]

Day, D. V., Gronn, P., \& Salas, E. (2004). Leadership capacity in teams. The Leadership Quarterly, 15, 857880. [Full text] [Back to text]

Day, C., Sammons, P., Hopkins, D., Harris, A., Leithwood, K., Gu, Q., Brown, E., Ahtaridou, E. \& Kington, A. (2009). The impact of school leadership on pupil outcomes. Department for Children, School and Families, DCSF Final Report. London: Department for Children, Schools and Families, DCSF, University of Nottingham and The National College for School Leadership. [Full text] [Back to text]
Eckel, P., Hill, B., \& Green, M. (1998). On change: En route to transformation .Washington, DC: American Council on Education. [Back to text]

Ensley, M. D., Hmieleski, K. M., \& Pearce, C. L. (2006). The importance of vertical and shared leadership within new venture top management teams: Implications for the performance of startups. The Leadership Quarterly, 17, 217-231. [Full text] [Back to text]

Feyerherm, A. E. (1994). Leadership in collaboration: A longitudinal study of two inter-organizational rulemaking groups. The Leadership Quarterly, 5, 253270. [Abstract] [Back to text]

Filan, G. L. \& Seagren, A.T. (2003). Six critical issues for midlevel leadership in postsecondary settings. New Directions for Higher Education, 124, 21-31. [Full text] [Back to text]

Gallagher, T, Griffin, S., Ciuffetelli Parker, D., Kitchen, J. \& Figg, C. (2011). Establishing and sustaining teacher educator professional development in a self-study community of practice: Pre-tenure teacher educators developing professionally. Teaching and Teacher Education, 27, 880-890. [Full text] [Back to text]

Gronn, P. (2002). Distributed leadership as a unit of analysis. The Leadership Quarterly, 13, 423451. [Back to text]

Hanna, D.E. (1998). Higher Education in an Era of Digital Competition: Emerging Organizational Models. Journal of Asynchronous 
Learning, 2 (1), 66-95. [Full text] [Back to text]

Hanna, D. E. (2003). Building a leadership vision. Eleven strategic challenges for Higher Education. Educause review, July/August, 2003. [Abstract] [Back to text]

Isaacs, W. (1999). Dialogue: the art of thinking together. New York: Broadway Business. [Back to text]

Keith, A. \& Levin, L. (2002). The five practices of exemplary leadership. In J. M. Kouzes \& B. Z. Posner (Eds.), Leadership Challenge (pp. 3-20). San Francisco: Jossey Bass. [Back to text]

Kelly, M. L. (2003). Academic advisers as transformational leaders: The mentor. Academic Advising Journal. Available online at: http://www.psu.edu/dus/mentor/0 30101mk.htm (accessed 12 august 2008) [Back to text]

Kennedy, C. \& Kennedy, J. (1996). Teacher Attitudes and Change Implementation. Elsevier Science Ltd, 24, 351-360. doi: 10.1016/0346-251X(96)00027-9 [Full text] [Back to text]

Kezar, A. \& Eckel, P. D. (2002). The effect of institutional culture on change strategies in Higher Education: Universal principles or culturally responsive concepts? The Journal of Higher Education, 73, 435-460. [Full text] [Back to text]

Kezar, A. J., Carducci, R. \& ContrerasMcGavin, M. (2006). Rethinking the "L" word in Higher Education. The revolution of research on leadership. ASHE Higher Education Report, San
Francisco: Jossey Bass. [Abstract] [Back to text]

Koen, M.P. \& Bitzer, E.M. (2010). Academic leadership in Higher Education: A "participative" perspective from one institution. Academic Leadership, 8 (3). [Back to text]

Krahenbuhl, G. S. (2004). Building the academic deanship. Strategies for success. Westport: Praeger. [Full text] [Back to text]

Kubitskey, B. \& Fishman, B.J. (2006). Professional development design for systemic curriculum change (pp. 1-26). American Educational Research Association AERA, The Center for Highly Interactive Classroom, Curricula and Computing in Education, Michigan. University of Michigan. [Full text] [Back to text]

Lees, N. D. (2006). Chairing academic departments. Traditional and emerging expectations. Bolton: Anker). [Back to text]

Leithwood, K., Mascall, B. \& Strauss, T. (2009). (Eds.). Distributed leadership according to the evidence. London: Routledge. [Full text] [Back to text]

Lueddeke, G. R. (1999). Toward a constructivist framework for guiding change and innovation in Higher Education. The Journal of Higher Education, 70, 235-260. [Abstract] [Back to text]

Middlehurst, R. (1997). Reinventing Higher Education: The leadership challenge. Quality in Higher Education, 3, 183-198. [Abstract] [Back to text]

Morrill, R. L. (2007). Strategic leadership. Integrating strategy 
and leadership in colleges and universities. Westport: Praeger Publishers. [Full text]

[Back to text]

Morrish, I. (1976). Aspects of Education Change. London: Unwin.

[Full text] [Back to text]

Nehring, J., Laboy, W.T. \& Catarius, L. (2010). Connecting reflective practice, dialogic protocols, and professional learning. Professional Development in Education,36(3), 399-420. [Abstract] [Back to text]

Nichols, A. (1983). Managing educational innovations .London: Allen \& Unwin. [Back to text]

Pearce, C. L. \& Sims, H. P. Jr. (2002). Vertical versus shared leadership as predictors of the effectiveness of change management teams: An examination of aversive, directive, transactional, transformational, and empowering leader behaviors. Group Dynamics: Theory, Research, and Practice, 6, 172197. [Abstract] [Back to text]

Pearce, C. L. (2004). The future of leadership: Combining vertical and shared leadership to transform knowledge work. Academy of Management Executive, 19, 47-57. [Abstract] [Back to text]

Petrov, G. (2006). The leadership foundation research on collective leadership in Higher Education. Leadership Matters, 7(11), 11. [Back to text]

Pisano, G. P. \& Verganti, R. (2008). Which kind of collaboration is right for you? Harvard Business Review, 86(12), 78-86. [Full text] [Back to text]
Pont, B., Nusche, D. \& Moorman, H. (2008). Improving school leadership. Volume 1: Policy and practice. Paris: Organization for Economic Co-operation and Development, OECD. [Full text] [Back to text]

Ramsden, P. (1998). Learning to lead in Higher Education. London: Routledge. [Full text] [Back to text]

Schon, D. (1983). The reflective practitioner: how professionals think in action. New York: Basic Books. [Full text] [Back to text]

Scott, S. (2010). Pragmatic Leadership Development in Canada: investigating a mentoring approach. Professional Development in Education, 36(4), 563-579. [Abstract] [Back to text]

Seashore-Louis, K., Leithwood, K., Wahlstrom, K. L. \& Anderson, S. E. (2010). Learning from leadership: investigating the links to improved student learning. The Wallace Foundation Center for Applied Research and Educational Improvement/University of Minnesota. [Full text] [Back to text]

Senge, P. (1990). The fifth discipline: the art and practice of the learning organization. New York: Currency. [Abstract] [Back to text]

Stenhouse, L. (1980). Introduction to Curriculum Research and Development. London: Heinemann. [Back to text]

Thomas, D. \& Brown, J. S. (2008). Why virtual world can matter. International Journal of Learning and Media, 1(1), 37-49. [Full text] [Back to text] 
Van Zyl, E. (2008). South African leadership for the twenty-first century: A self-leadership approach. Acta Academica, 40(4), 183-192. [Back to text]

Wasser, J.D. \& Bresler, L. (1996). Working in the Interpretative Zone: Conceptualizing Collaboration in Qualitative Research Teams. Educational
Researcher, 25(5), 5-15. [Abstract] [Back to text]

Wenger, E. (1998). Communities of Practice: Learning meaning and identity. Cambridge, Cambridge: University Press. [Full text] [Back to text]

Wenger, E. (2000). Communities of practice and social learning systems. Organization, 7(2), 225246. [Full text] [Back to text] 